\title{
QUISTE DE LA GLÁNDULA DE SKENE: 4 CASOS Y REVISION DE LITERATURA
}

Luis Busto Martín, lyad Barguti, Antón Zarraonandia Andraca, Ignacio Rodríguez Gómez y Luis Busto Castañón.

Complejo Hospitalario Universitario La Coruña. Clínica Urológica Dr. Busto. La Coruña. España.

Resumen.- OBJETIVOS: Presentar nuestra experiencia con cuatro casos de quistes de las glándulas de Skene de gran tamaño, realizar una revisión de la literatura publicada y conocer así los distintos diagnósticos diferenciales y el manejo a seguir.

MÉTODOS: Cuatro mujeres remitidas a nosotros desde su ginecólogo por presentar masas parauretrales refractarias a tratamiento conservador con posible afectación de la uretra distal.

CONCLUSIONES: El quiste de la glándula de Skene es una patología que raramente tratan los urólogos debido a su escasa repercusión clínica pero cuando nos es remitida por los ginecólogos es importante realizar un estudio completo del aparato urinario para realizar así un diagnóstico diferencial certero que excluya patologías malignas o alte-

\section{CORRESPONDENCIA}

Luis Busto Martín

Maestro Mateo 8, entr. izda.

La Coruña. (España)

lbm@urologíabusto.com

Aceptado para publicar: 14 de enero 2010 
raciones del aparato urinario. El tratamiento de elección en los casos refractarios es quirúrgico, realizando una exéresis completa del quiste y reparando las posibles lesiones de la pared uretral. En todos los casos la evolución fue favorable sin presentar recidiva o complicaciones fistulosas.

Palabras clave: Glándulas de skene. Glándulas parauretrales. Skenitis. Quiste.

Summary.- OBJECTIVES: To show our experience with 4 cases of cysts of the Skene's gland and a review of the published literature.

METHODS/RESULTS: Diagnosis and treatment of 4 cases of Skene's gland cyst.

CONCLUSIONS: Skene's gland cyst is a lesion that rarely is treated by Urologists, because it doesn't usually have clinical repercussion, but when it's derived to us we have to make a complete study of the urinary tract to exclude complications or different serious lesions. Surgery is the treatment of choice, making a complete excision of the lesion and repair of urethral injuries. All cases evolved well without recurrence or fistulous complications.

Keywords: Skene's gland. Paraurethral glands. Skenitis. Cyst.

\section{INTRODUCCIÓN}

Las glándulas de Skene, también conocidas como glándulas periuretrales o parauretrales femeninas son unas glándulas de pequeño tamaño (habitualmente en número de 4) que se localizan en la cúpula de la vagina, alrededor del borde ínfero distal de la uretra, y generalmente pasan desapercibidas excepto en casos de infección u obstrucción. Drenan en el borde externo de la uretra femenina y son las encargadas de la lubrificación de la uretra distal. Se han considerado el equivalente a la glándula prostática masculina, siendo las principales productoras de "PSA" en mujeres y las responsables de la eyaculación femenina $(1,2)$. Son unas glándulas hormono-dependientes, estando habitualmente hipertrofiadas en el embarazo y produciéndose una atrofia en el climaterio.

Los quistes parauretrales a partir de las glándulas periuretrales de Skene en mujeres constituyen una patología infrecuente, y aunque pueden aparecer en ocasiones desde el nacimiento (1:2000-1:7000 nacimientos vivos) (3) pasan en muchas ocasiones desapercibidas, ya que disminuyen de tamaño en las 4 primeras semanas, siendo entre 25 y los 34 años la edad de presentación más frecuente (4).

\section{CASO CLÍNICO}

Presentamos cuatro pacientes de 28, 31, 33 y 42 años respectivamente; estando la más joven embazada de 26 semanas. Dos de ellas consultan a su ginecólogo remitidas desde su médico de Atención Primaria por disuria de 4-6 semanas de duración, dispareunia ocasional y en los últimos días sensación de masa a nivel parauretral. Las otras dos restantes consultan únicamente a su ginecólogo por descubrir una masa a nivel parauretral. Dos de ellas previamente a su cita con su ginecólogo habían recibido tratamiento por su médico de Atención Primaria con Amoxicilina-clavulánico a dosis de $875 / 125 \mathrm{mg}$ durante una semana, obteniendo una mejoría parcial de los síntomas. El ginecólogo tras realizar una exploración de las pacientes y evidenciar la posible afectación uretral decide derivar al urólogo a las pacientes para realizar un estudio del aparato genitourinario, el diagnóstico y tratamiento de esta patología.

La exploración física de todas las pacientes era totalmente anodina, sin linfadenopatías inguinales ni lesiones en genitales externo; tampoco se observaron secreciones vaginales excesivas que nos hiciesen sospechar de una posible etiología infecciosa por contacto sexual. En las cuatro encontramos un nódulo liso, indoloro, de aspecto quístico, ligeramente fluctuante con tamaños variables (entre $1 \times 1$ y $4,1 \times 4,3 \mathrm{~cm}$ ) adherida a la uretra distal y que parecían formar parte de la misma (Figuras 1 y 2).

Solicitamos para las cuatro pacientes un cultivo de orina y de secreciones vaginales siendo en todos los casos los resultados negativos para ETS (N. Gonorrhoeae, Clamidias, .... , y apareciendo en una de ellas infección urinaria por E. Coli. También solicitamos en todos los casos una uretrocistografía retrógrada (Figura 4) comprobando en uno de los casos que el quiste de la glándula de Skene producía una pequeña estenosis uretral sin ninguna relevancia clínica. La uretra estaba íntegra en todos los casos y la vejiga presentaba características normales. Esto nos permitió descartar la posibilidad de un ureterocele, razón principal por la que el ginecólogo nos derivó estas pacientes.

Inicialmente instauramos un tratamiento conservador con higiene, antibioterapia e intento de drenaje manual sin éxito, por lo que decidimos preparar a las pacientes para una excisión completa de los quistes bajo anestesia.

Realizamos las cirugías bajo anestesia locorregional, en dos casos inyectando en el quiste azul de metileno para delimitarlo bien, y en los otros dos bajo visión directa, colocando en todas un catéter uretral para preservar la uretra y realizamos una exéresis completa de los quistes mediante tijera de Metzembaum, con apertura intraoperatoria en dos de los casos y los cuales drenaron un contenido de aspecto lechoso-purulento (Figuras 1, 2 y 3). Remitimos a Anatomía patológica las piezas y mandamos a microbiología los contenidos de los quistes. 
Los resultados fueron siempre de quistes recubiertos de epitelio escamoso estratificado, con lámina basal bien formada y microvillis prominentes con contenido hemato-purulento (achocolatado). El análisis microbiológico también fue negativo para todo tipo de ETS.

Dos de las pacientes permanecieron con el catéter uretral de $18 \mathrm{Fr}$. durante una semana para preservar la estructura de la uretra, ya que en estas dos pacientes la pared del quiste estaba íntimamente adherida a la pared uretral y durante su escisión se daño la misma, precisando reparación con una sutura reabsorbible. Posteriormente a su retirada y con un periodo de seguimiento de entre 8 meses y 4 años las pacientes han permanecido asintomáticas hasta la actualidad sin mostrar ningún indicio de recidiva o complicación fistulosa.

\section{DISCUSIÓN}

La patología de las glándulas de Skene no es habitual, ya que en la mayoría de las ocasiones los pequeños quistes pasan desapercibidos, a no ser que existan complicaciones: cuando se infectan $u$ obstruyen, dichas glándulas, que rara vez son perceptibles, se agrandan e inflaman, dando lugar a lo que se conoce como Skenitis.

Dicha patología es habitualmente diagnosticada y tratada por los ginecólogos, sólo derivándose al urólogo cuando adquiere un tamaño suficiente que pueda comprimir la uretra, o se sospeche otra patología de mayor importancia como sería un divertículo uretral o un tumor parauretral, que aunque tienen escasa prevalencia tienen una importante repercusión sobre el sistema urinario.

Existen múltiples causas que originan la formación de los quistes: traumatismos mecánicos o la obstrucción por cuerpo extraño, o infecciones repetidas que producen aumento del diámetro de las glándulas y formación de epitelio escamoso estratificado que acaba originando un quiste suburetral o un absceso $(1,2)$. Es posible que dicha cavidad se rompa comunicando la luz uretral y el quiste. La clínica habitual suele ser: sensación de cuerpo extraño $(100 \%)$, clínica irritativa miccional $(78 \%)$, dispareunia $(26 \%)$, dificultad miccional $(15 \%)$ y secreción.

La uretrocistoscopia y uretrocistografía retrógrada (sensibilidad $100 \%$ ) son exploraciones necesarias para descartar la comunicación con la uretra la vejiga o la vagina y poder también estudiar el grado de obstrucción existente $(3,4)$.

Es importante realizar un diagnóstico diferencial de otras masas de la pared anterior de la vagina como ureterocele, divertículo uretral, quiste de Gardner, quiste epidérmico, quiste endometriosico y con tumores

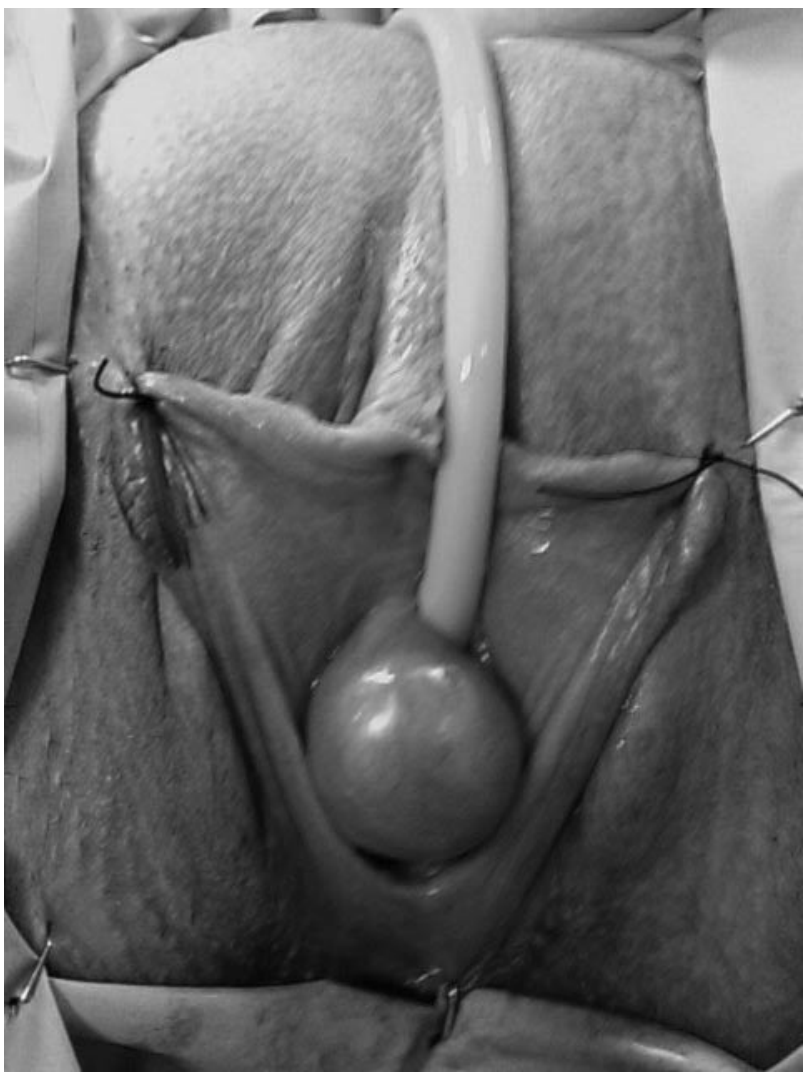




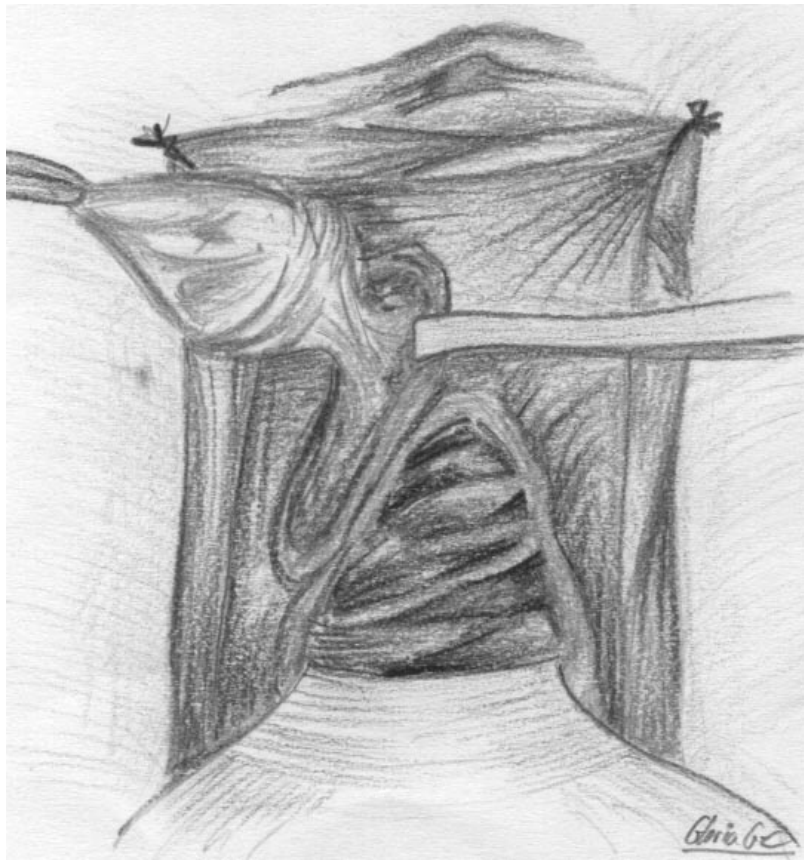

FIGURA 2. Exéresis de masa.

uretrales y parauretrales (como los adenocarcinomas, $<0,003 \%$ de los tumores del TGU en la mujer) $(5,6)$. Para ello nos basamos en su localización y posteriormente en su confirmación anatomopatológica (7):

- Pared vaginal anterior: quiste de Gardner (de restos mesonéfricos), quiste Mülleriano (de restos paramesonéfricos)

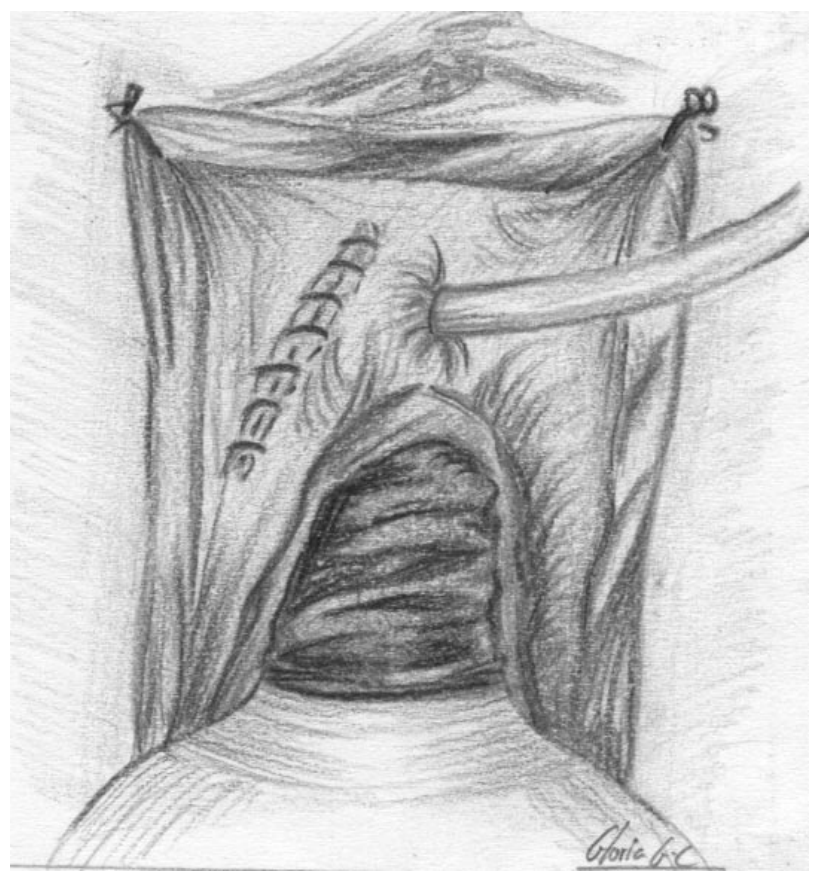

- Pared lateral de introito: quiste de Bartholin

- Pared anterior y posterior de vagina: ureterocele/cistocele/ rectocele

- Suelo de uretra distal: quiste de las glándulas de Skene.

- Pared posterior y lateral de uretra: divertículo uretral Siempre hay que pensar en la probabilidad de ETS, puesto que en la gonorrea estas glándulas parecen estar casi siempre afectadas. En este caso el tratamiento antibiótico ideal podría ser una cefalosporina de $3^{\text {ㅇ }}$ generación en dosis única junto con una tetraciclina 1 semana o azitromicina. También se ha visto útil el uso de ciprofloxacino $u$ ofloxacino en una dosis (3).

En neonatos el tratamiento puede ser expectante ya que estos quistes tienden a disminuir de tamaño las cuatro primeras semanas de vida haciéndose imperceptibles.

En adolescentes y adultos cuando el tratamiento médico no es efectivo y sobre todo cuando los quistes adquieren gran tamaño y producen clínica, la exéresis quirúrgica parece el tratamiento de elección (7). Se debe evitar la lesión de la uretra $(10 \%)$ y si es así repararla lo antes posible y dejar un catéter ureteral durante 1-2 semanas. A veces si el quiste es pequeño con la apertura del quiste $y$ un drenaje completo puede ser suficiente.

\section{CONCLUSIONES}

La presentación clínica de un quiste de las glándulas de Skene es algo que un Urólogo pocas veces ve a lo largo de su carrera profesional, siendo posiblemente una patología infraestimada debido a la variabilidad de la clínica que en muchas ocasiones (a falta de existir una

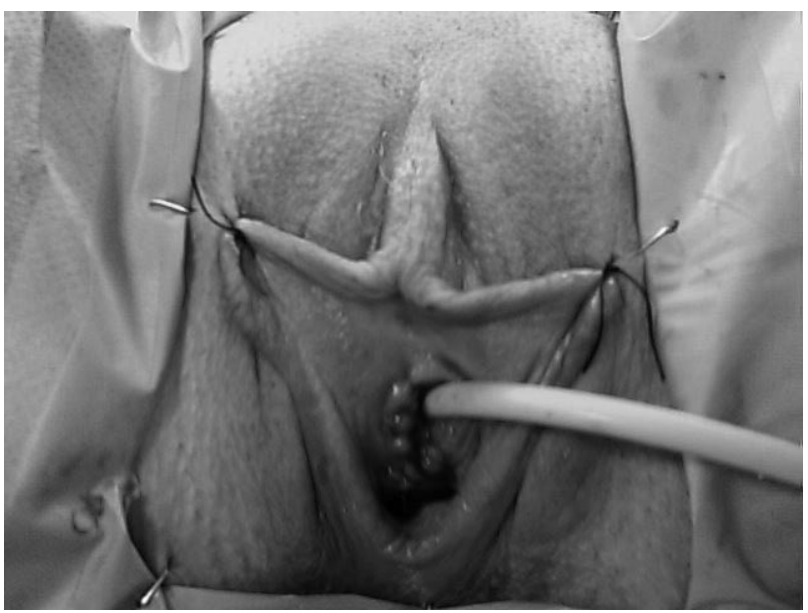


masa visible) es tratada como una infección urinaria y resolviéndose la patología de forma empírica.

En la mayoría de los casos que un urólogo recibe a estas pacientes derivadas desde su ginecólogo se debe a la necesidad realizar un diagnóstico diferencial correcto y un estudio completo de la vía urinaria pudiendo realizar así un diagnóstico y un manejo adecuado de la patología.

Según nuestra experiencia la punción del quiste suele presentar importante número de recidivas y posible infección del mismo. Únicamente en los casos en donde el manejo conservador ha fracasado deberemos realizar un tratamiento quirúrgico basado en una escisión completa del quiste, el cual si se realiza previo estudio completo urológico, tiene muy buenos resultados y con pocas probabilidades de recidiva y complicaciones casi inexistentes, las cuales si son detectadas (como la lesión de la uretra distal que ocurre en el $10 \%$ ) y reparadas inmediatamente no empeoran los resultados.

\section{BIBLIOGRAFÍA y LECTURAS RECOMENDADAS (*lectura de interés $y^{* *}$ lectura fundamental)}

1. Asper A, Rackley R and Vasavada S. (2002) Contemporany evaluation and management of the female urehral diverticulum. Urol Clin. North Am, 1998; 29(3):617-624.

*2. Miranda EP, Almeida DC, Ribeiro GP, Parente JM and Scafuri AG. Surgical treatment for recurrent refractory skenitis. TSW Urology, 2008; 658-660.

3. Soria GR, González A, Jaspersen J. Quistes parauretrales. Reporte de 19 casos y revisión de la literatura. Rev Mex Urol, 2005; 65(1): 60-5.

**4. Reyes GM, Reyna PR, Sanchez OJ, García MS, Quistes parauretrales. Presentación de dos casos y revisión de la literatura. Rev Mex Urol, 2000; 60(2): 87-91.

5. Durel P. (1951) Broad exposure for skenitis and bartholinitis. Gynecol, 1995; Prat 2(3), 389-392.

6. Izquierdo C, Rodriguez P, Sabanés ME, Navarro F, and Sánchez F. Gardenella Vaginalis skenitis. Enferm. Infecc. Microbiol. Clin, 1996; 14(3), 199-200.

7. Romero Reyes R, Rodriguez Colorado S, Escobar del Barco L, Gorbea Chávez V. Quiste suburetral. Reporte de un caso. Ginecol Obstet Mex, 2009; 77(3): 160-4. 